\title{
Development, Linkage Mapping, and Use of Microsatellites in Bermudagrass
}

\author{
Karen R. Harris-Shultz ${ }^{1}$ \\ USDA-ARS, Crop Genetics and Breeding Research Unit, P.O. Box 748, Tifton, GA 31793 \\ Brian M. Schwartz and Wayne W. Hanna \\ Department of Crop and Soil Sciences, University of Georgia, Tifton Campus, P.O. Box 748, Tifton, \\ GA 31793
}

Jeff A. Brady

Texas AgriLife Research, 1229 N. US Highway 281, Stephenville, TX 76401

\begin{abstract}
AdDitional INDEX words. Cynodon, EST-SSR, genetic mapping, SDAF
Abstract. Genetic linkage maps of bermudagrass (Cynodon spp.) species using 118 triploid individuals derived from a cross of T89 [C. dactylon $(2 \mathrm{n}=4 \mathrm{x}=36)]$ and T574 [C. transvaalensis $(2 \mathrm{n}=2 \mathrm{x}=18)]$ were enriched with expressed sequence tags-derived simple sequence repeat (EST-SSR) markers. Primers were developed from 53 ESTs containing SSRs producing 75 segregating markers from which 28 could be mapped to the T89 and T574 genetic maps. With the addition of previously generated marker data, 26 T89 linkage groups and eight T574 linkage groups were formed using a log-of-odds (LOD) value of 4.0. The T89 and T574 linkage maps spanned $1055 \mathrm{cM}$ and $311.1 \mathrm{cM}$ and include 125 and 36 single-dose amplified fragments (SDAFs), respectively. Many of the SDAFs displayed disomic segregation and thus T89 may be a segmental allotetraploid or an allotetraploid. The additional EST-SSR markers add value to the maps by increasing marker density and provide markers that can be easily transferred to other bermudagrass populations. Furthermore, EST-SSRs can be immediately used to assess genetic diversity, identify non-mutated cultivars of bermudagrass, confirm pedigrees, and differentiate contaminants from cultivars derived from 'Tifgreen'.
\end{abstract}

Bermudagrass is a warm-season grass used as turf for home lawns, public parks, golf courses, sports fields, and for forage and soil conservation (Zhang et al., 1999). Common bermudagrass [Cynodon dactylon $(2 \mathrm{n}=4 \mathrm{x}=36)$ ] was first introduced into the United States during the colonial period (Kim et al., 2008) and has spread throughout the southern United States. Cultivar releases from Tifton, GA, are predominantly generated by crossing african bermudagrass [Cynodon transvaalensis $(2 \mathrm{n}=2 \mathrm{x}=18)$ ] with common types to produce sterile triploid hybrids with improved turf qualities, although other turfgrass breeding programs have recently developed improved vegetatively or seed-propagated tetraploid cultivars (Riley, 2000; Taliaferro et al., 2003).

Bermudagrass has many advantageous traits promoting its pervasive use. Bermudagrass is salt-tolerant (Kim et al., 2008), heat- and drought-tolerant (Utrillas and Alegre, 1997; Walker et al., 2006), and has the ability to spread by stolons, rhizomes, and seeds (Webster et al., 2004). Despite these many qualities, the genes controlling these traits have not been identified and few molecular tools have been developed.

Although bermudagrass species are often polyploid, a framework genetic linkage map has been constructed based on singledose restriction fragments (SDRFs) (Bethel et al., 2006). SDRFs or alternatively single-dose amplification fragments markers (Stein et al., 2007) are present as a single copy on a single chromosome from only one of the parents in the cross. Because

Received for publication 18 May 2010. Accepted for publication 23 Aug. 2010. We are grateful to Mrs. Jacolyn Merriman for technical assistance and Dr. Joanne Conner and Dr. Andrew Paterson for thoughtful suggestions.

Mention of trade names or commercial products in this publication is solely for the purpose of providing specific information and does not imply recommendation or endorsement by the U.S. Department of Agriculture.

${ }^{1}$ Corresponding author. E-mail: Karen.Harris@ars.usda.gov.
SDAFs are present in a 1:1 ratio in the gametes, they can be used for mapping in polyploids regardless of ploidy level or chromosomal pairing (auto versus allo) (Wu et al., 1992). With SDAF mapping, a linkage map is generated for each parent separately (Fregene et al., 1997). Four homologous sets were formed for the T89 (tetraploid) parental map using 155 SDRFs (Bethel et al., 2006). For the T574 (diploid) parental map, 77 SDRFs formed seven homologous sets (Bethel et al., 2006). With the T89 and T574 maps having $61 \%$ and $62 \%$ marker coverage of their genomes (Bethel et al., 2006), respectively, additional markers are needed to fill in gaps as well as to link homologous linkage groups. Recently, bermudagrass resistance gene analogs were identified and added to the map (Harris et al., 2010). Increased marker density is needed to map traits of interest such as nematode tolerance, root length, and turf quality that may be different between the two parents. Thus, the objective of this research was to develop EST-SSR markers that can be used to identify homologous linkage groups and enrich the bermudagrass genetic map. Furthermore, these SSR markers were evaluated to determine if differences can be generated between a set of very closely related genotypes and for the identification of contaminants among monoculture plantings.

\section{Materials and Methods}

Plant material. W. Hanna (University of Georgia, Tifton, GA) created the T89 [C. dactylon $(4 \mathrm{x})] \times \mathrm{T} 574$ [C. transvaalensis (2x)] triploid mapping population (Bethel et al., 2006). Nodes from bermudagrass cultivars Tifgreen, JonesDwarf, FloraDwarf, Tifdwarf, TifEagle, Champion, Tifway, Tifway II, TifSport, and TifGrand were obtained from B. Schwartz (University of Georgia, Tifton, GA). Two off-types (MiniVTL1, MiniVTL2) and a control (MiniVTL-TX) of 'MiniVerde' were donated by 
Table 1. Primers developed to amplify 53 expressed sequence tags containing simple sequence repeats.

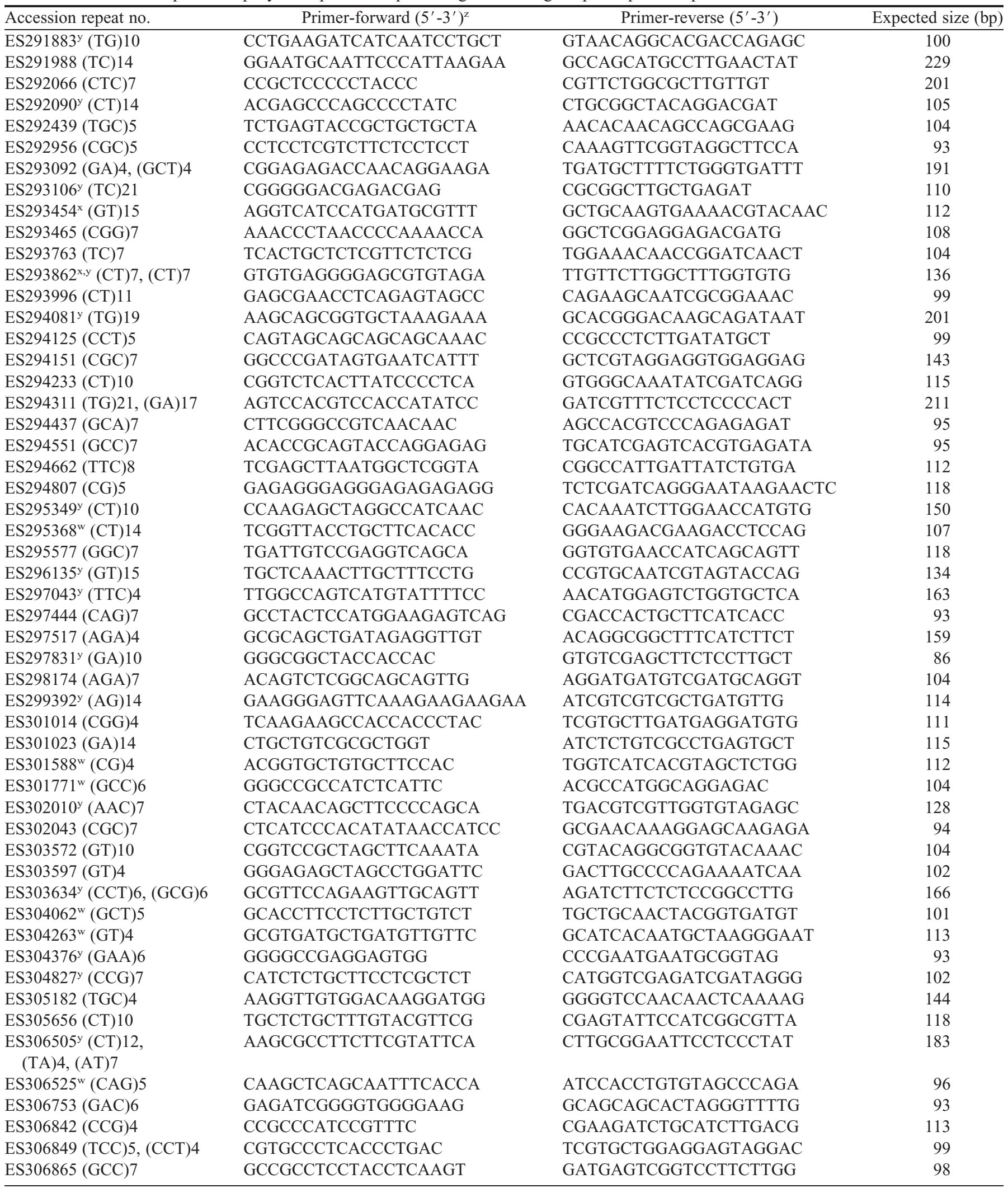

${ }^{\mathrm{z} F o r w a r d ~ p r i m e r s ~ a r e ~ l a b e l e d ~ w i t h ~ a ~ M 13 ~ t a g ~(T G T A A A A C G A C G G C C A G T) . ~}$

${ }^{\mathrm{y}}$ Generates a codominant marker originating from T89.

${ }^{\mathrm{x}}$ Generates a codominant marker originating from T574.

${ }^{\mathrm{w}}$ Annealing temperature was $50{ }^{\circ} \mathrm{C}$ for all primers except these that had an annealing temperature of $60{ }^{\circ} \mathrm{C}$. 
T. Lowe (U.S. Golf Assn., Far Hills, NJ). Plugs from two 'Tifdwarf' off-types (BT1, BT3) and two control 'Tifdwarf' samples (BT2, BT4) from putting green 13 (BT1, BT2) and 17 (BT3, BT4) were sent from a Florida golf course.

Ploidy analysis. Triploid ploidy levels were confirmed for each individual of the mapping population using flow cytometry. Fresh tissue $\left(\approx 0.5 \mathrm{~cm}^{2}\right)$ was isolated from potted accessions and chopped using a double-edged razor in 600 $\mu \mathrm{L}$ of nuclei extraction buffer solution (Partec, Munster, Germany) to release the nuclei. The slurry was poured through a $50-\mu \mathrm{m}$ filter and $1.6 \mathrm{~mL}$ of Partec DAPI staining buffer was added. The nuclei were analyzed on a Partec Cell Analyzer PAS-III flow cytometer and at least 5000 fluorescent particles were counted. T89 and T574 were used as controls. Triploid ploidy level was confirmed by adding T89, T574, and each $\mathrm{F}_{1}$ progeny to the sample and confirming the unknown Gap1 $\left(\mathrm{G}_{1}\right)$ peak was between the control $\mathrm{G}_{1}$ peaks.

Simple SEQUenCE REPEAT GENERATION. DNA was extracted from $118 \mathrm{~F}_{1}$ field-grown individuals using a PureLink DNA Purification Kit (Invitrogen, Carlsbad, CA). From genotype T89, 143 EST sequences containing SSRs were identified but not verified by polymerase chain reaction (PCR) (Kim et al., 2008). Primers were designed using Primer 3 (Rozen and Skaletsky, 2000) to flank the SSR sequence from 53 of these ESTs (Table 1). SSRs were amplified and fluorescently labeled for detection using a modified M13-tailed primer method (Boutin-Ganache et al., 2001). PCR reactions were in a $10-\mu \mathrm{L}$ volume and contained $2 \mu \mathrm{L}$ of $5 \times$ Clear GoTaq ${ }^{\circledR}$ reaction buffer (Promega, Madison, WI), $1 \mu \mathrm{L}$ of $25 \mathrm{~mm} \mathrm{MgCl}_{2}, 0.8 \mu \mathrm{L}$ of $2.5 \mathrm{~mm}$ dNTP mix, $1.0 \mu \mathrm{L}$ of pooled M13-tagged forward primer and reverse primer at $1 \mu \mathrm{M}, 1.0 \mu \mathrm{L}$ of $1 \mu \mathrm{M}$ M13 primer (M13TGTAAAACGACGGCCAGT) fluorescently labeled with the IRDye ${ }^{\circledR}$ 800 or $700 \mathrm{CW}$ fluorophore (Eurofins MWG Operon, Huntsville, AL), $0.04-\mu \mathrm{L}$ of GoTaq ${ }^{\circledR}$ DNA polymerase (Promega), $3.16 \mu \mathrm{L}$ of sterile water, and $1 \mu \mathrm{L}$ of $2.5 \mathrm{ng} \cdot \mu \mathrm{L}^{-1} \mathrm{DNA}$. Thermocycler conditions were an initial denaturation at $94{ }^{\circ} \mathrm{C}$ for $3 \mathrm{~min}, 39$ cycles of $94{ }^{\circ} \mathrm{C}$ for $30 \mathrm{~s}$, 50 or $60^{\circ} \mathrm{C}$ (see Table 1 ) for $1 \mathrm{~min}$, $72{ }^{\circ} \mathrm{C}$ for $1 \mathrm{~min}$ and $10 \mathrm{~s}$, and a final elongation step at $72{ }^{\circ} \mathrm{C}$ for $10 \mathrm{~min}$. Two microliters of PCR product were combined with $5 \mu \mathrm{L}$ of Blue Stop (LI-COR $®$ Biosciences, Lincoln, NE) and $0.35 \mu \mathrm{L}$ of this mixture was loaded on a $6.5 \%$ acrylamide gel using a LI-COR® Biosciences 4300 DNA Analyzer (Lincoln, NE). Gel images were scored visually.

LiNKAGE MAPPING. SSR marker segregation data from the $118 \mathrm{~F}_{1}$ progeny were recorded into an Excel worksheet (Microsoft, Redmond, WA) using Joinmap®4 (Van Ooijen, 2006) genotype codes for a $\mathrm{BC}_{1}$ population. SSR marker data were combined with restriction fragment length polymorphism (RFLP) data from Bethel et al. (2006). Those markers showing segregation distortion, as determined by $\chi^{2}$ analysis with a significance level of 0.05 or less were excluded from mapping. A LOD of 4 was used for grouping. Map distances were derived using the Kosambi mapping function (Kosambi, 1944).

AMPLIFIED FRAGMENT LENGTH POLYMORPHISM GENERATION AND ANALYSIS. An amplified fragment length polymorphism (AFLP) template was generated for 14 triploid hybrids (Table 2) and fragments were resolved as previously described (Harris et al., 2009). Polymorphic markers were identified from the following selective amplification primer combinations: E-AAC M-CAT, E-AAC M-CTC, E-AAC M-CTT, E-AAG M-CTA, EACA M-CAA, E-ACC M-CTT, E-AGG M-CAA, E-AGG MCAC, E-AGG M-CAG, E-AGG M-CAT, and E-ECG M-CAT. Presence or absence of fragments was determined visually and coded as " 1 " for presence of a band, " 0 " for lack of a band for each accession for each marker, or "9" for missing data. A genetic similarity matrix was generated among all pairs of lines by using the Dice coefficient of similarity (Nei and Li, 1979). A dendrogram was created from the similarity matrix by using the unweighted pair group method with averages procedure in the SAHN module of NTSYSpc (Rohlf, 2008). Bootstrap resampling was performed using the software program FreeTree (Hampl et al., 2001) with 500 bootstrap repetitions.

IDENTIFICATION OF POLYMORPHIC FRAGMENTS AMONG 'Tifgreen'-DERIVEd MUtANTS AND CONTAMinants. Amplicons were generated from primers designed to the 53 ESTs containing SSRs from a single sample of 'Tifgreen', 'Tifdwarf', two 'Tifdwarf' off-types (BT1, BT3) and two control 'Tifdwarf' samples (BT2, BT4), 'FloraDwarf', 'Jones Dwarf', 'Champion', 'MiniVerde', two off- types and a control of 'MiniVerde', and

Table 2. Triploid bermudagrass hybrids used in this study for cultivar identification.

\begin{tabular}{|c|c|c|}
\hline Cultivar/off-type & Derived & $\begin{array}{l}\text { Pedigree agrees with } \\
\text { AFLP and SSR data? }\end{array}$ \\
\hline BT1 & Off-type in 'Tifdwarf' green $13^{z}$ & No \\
\hline BT2 & Control in 'Tifdwarf' green $13^{z}$ & Yes \\
\hline BT3 & Off-type in 'Tifdwarf' green $17^{z}$ & Yes \\
\hline BT4 & Control in 'Tifdwarf' green $17^{\mathrm{z}}$ & Yes \\
\hline Champion & Off-type of 'Tifdwarf' putting green ${ }^{y}$ & Yes \\
\hline FloraDwarf & Off-type in 'Tifgreen' practice green ${ }^{y}$ & Yes \\
\hline JonesDwarf & Off-type of 'Tifdwarf' & Yes \\
\hline MiniVerde & Off-type of 'Tifdwarf' & Yes \\
\hline MiniVerde TL-TX & Control 'MiniVerde' ${ }^{\mathrm{x}}$ & Yes \\
\hline MiniVerde TL1 & Off-type of 'MiniVerde'x & Yes \\
\hline MiniVerde TL2 & Off-type of 'MiniVerde'x & Yes \\
\hline Tifdwarf & Off-type of 'Tifgreen' & Yes \\
\hline TifEagle & Irradiated mutant of 'Tifway II' & No \\
\hline TifGrand & $\begin{array}{l}\text { Cynodon transvaalensis } \times \\
\text { Cynodon dactylon }\end{array}$ & Yes \\
\hline Tifgreen & C. transvaalensis $\times$ C. dactylon & Yes \\
\hline Tifway & $\begin{array}{l}\text { C. transvaalensis } \times \text { C. dactylon seed } \\
\text { from Africa }\end{array}$ & Yes \\
\hline Tifway II & Irradiated mutant of 'Tifway' & Yes \\
\hline TifSport & Irradiated mutant of 'Midiron' & No \\
\hline
\end{tabular}

${ }^{\mathrm{z}}$ Sample from putting green at Baytree National Golf Course, Melbourne, FL.

${ }^{y}$ Sample obtained by B. Schwartz (Tifton, GA) from the University of Florida Plant Science Research and Education Unit, Citra, FL.

${ }^{x}$ Sample from Heritage Palms Golf and Country Club, Fort Myers, FL.

$\mathrm{AFLP}=$ amplified fragment length polymorphism; SSR = simple sequence repeat. 
'TifEagle'. The triploid cultivars Tifway, Tifway II, TifGrand, and TifSport also were amplified as well for possible off-type identification. A genetic similarity dendrogram was created using the NTSYSpc program as described previously.

\section{Results and Discussion}

Simple SEQuence Repeat AMPLification. Primers were developed from 53 EST sequences containing SSRs (Table 1) that produced 110 polymorphic markers. Six primers (ES293763, ES294233, ES301014, ES293092, ES306849, ES294807) failed to produce an amplicon of sufficient quality. Of these 110 markers, 35 markers displayed either mostly a T89 allele (26) or a T574 allele (nine) in the triploid progeny (all progeny were confirmed as triploids using flow cytometry) and were discarded. These markers that display mostly one allele in the triploid progeny are likely in triple or quadruple dose for T89 or are homozygous in T574. Seventy-five SSR markers were segregating in the progeny, but using a $\chi^{2}$ test (with a $\chi^{2}$ significance level of 0.05 or less), 11 of the EST-SSR markers were significantly skewed from 1:1 segregation.

Genetic MaPPING. Many of the EST-SSR markers were codominant markers with a parental origin from T89 (15) or T574 (two) (markers listed in Table 1). Of interest, these codominant markers from T89 had disomic inheritance (Fig. 1) and no heterozygous $F_{1}$ progeny were seen for the 15 markers except for individual B17-26 for EST-SSR marker ES293862. This information suggests that tetraploid $C$. dactylon var. dactylon genotypes (i.e., T89) may be a segmental allotetraploid or allopolyploid rather than an autotetraploid (Bethel et al., 2006). Segmental allopolyploid behavior occurs when some sets of chromosomes are well-differentiated and exhibit disomic behavior, whereas other sets show little differentiation and display tetrasomic inheritance (Rieseberg and Noyes, 1998). RFLP and EST markers displaying disomic inheritance were located on the T89 map and mapped on linkage groups 1a (RZ476b, ES296135-A), 1c (RZ142b, ES293106-C, ES294081-B), 2a (ES306505, ES306865-A, RZ596a, T5745D12c, T5748G06b), 3a (T5745A03a, ES295349-B), 5a and 15 (T5742C08a, ES297831-B, ES304827-B, T5741G08b), 7a (ES291883-A, PCD137a), and 8b (T5741A08e, T5745F10d, ES299392-B). Single markers with disomic inheritance on individual linkage groups were seen on 3c (PCD070a), 4a (T5746B12a), 4c (T5741E07a), 6a (T5745F06b), 16 (T5741D01b), 20 (T5745B09a), 21 (ES293862-D), 22 (ES303634), and 23 (ES297043-C). The clustering of markers with disomic segregation for the T89 genetic map suggests a segmental allopolyploid, but the number of mapped markers is quite low and additional markers with disomic inheritance may map to all linkage groups, which would suggest allopolyploidy. Two methods have been used to distinguish autopolyploids and allopolyploids using molecular markers. One is by comparing the proportion of single- to multiple-dose markers (Da Silva et al., 1993) and the other is by comparing the number of loci linked in coupling with the number of loci linked in repulsion (Wu et al., 1992). The expected proportion of non-SDAF markers in the gametes of an autotetraploid is 0.17 , whereas the expected ratio in an allotetraploid is 0.25 (Missaoui et al., 2005). Examination of all markers used showed the proportion of non-SDAF as 0.39 . Thus, this technique was not useful for polyploidy determination in our

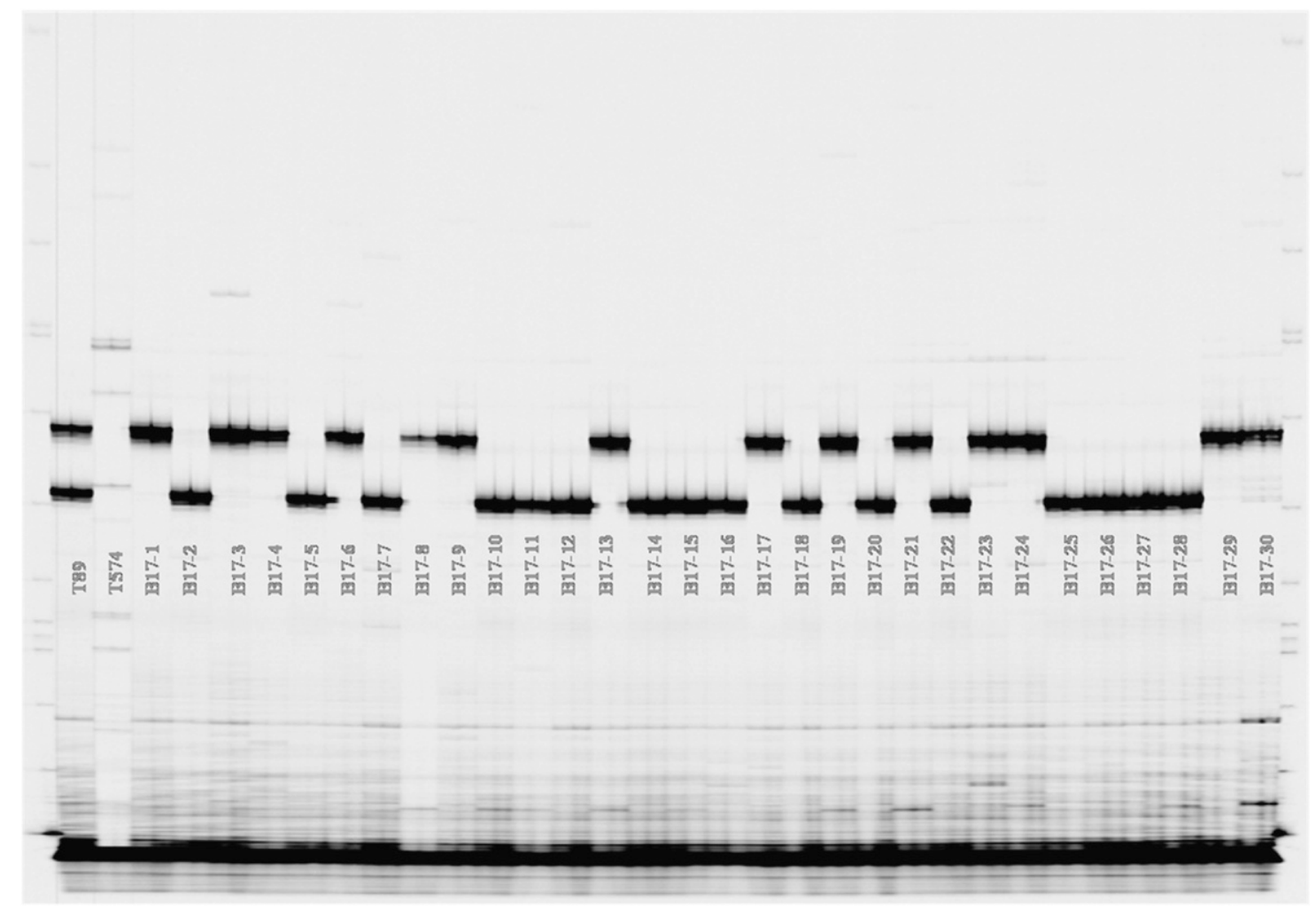

Fig. 1. A codominant expressed sequence tag-simple sequence repeat (EST-SSR) marker ES295349, originating from parent T89, was amplified using the B17-F1 bermudagrass population as a template (shown here are individuals 1 to 30). The T89 allele sizes are 147 and $172 \mathrm{bp}$. The 50- to 350-bp size standards were loaded in the first and last lanes. 
study nor did it give a clear delineation of alloploid versus autoploid when RFLPs were used in switchgrass (Missaoui et al., 2005). To compare the number of markers linked in coupling with the number of loci linked in repulsion, a genetic map was created using markers in the coupling and repulsion phase. The number of markers linked in coupling to repulsion for this genetic map was 85:100 (Supplementary Fig. 1). The expected ratio for an allopolyploid and an autotetraploid is $1: 1$ and $0.25: 1$, respectively. Thus, T89 appears to be segregating as an allopoly- ploid $\left(\chi^{2}=1.216, P=0.2701\right)$, which is in agreement with the meiotic chromosome behavior (Forbes and Burton, 1963; Hanna and Burton, 1977). Indeed, this technique has been used to determine the type of chromosome assortment in a variety of polyploids such as sugarcane (Saccharum spontaneum) (Al-Janabi et al., 1993). Furthermore, disomic inheritance of markers limits the usefulness of codominant markers in identifying homologous linkage groups because these markers map to a single locus.
$1 \mathrm{a}$

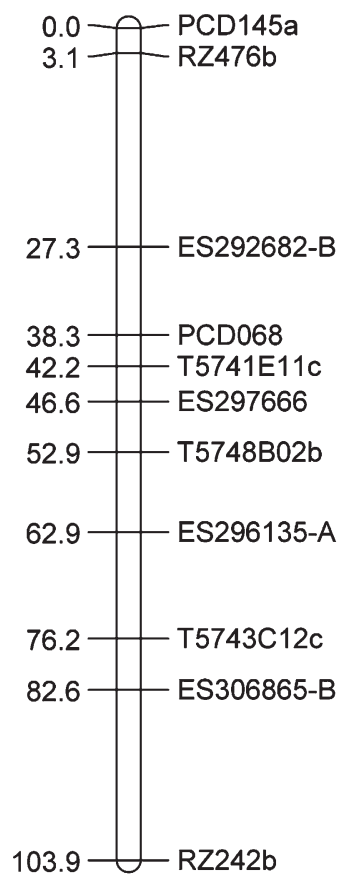

$1 c$

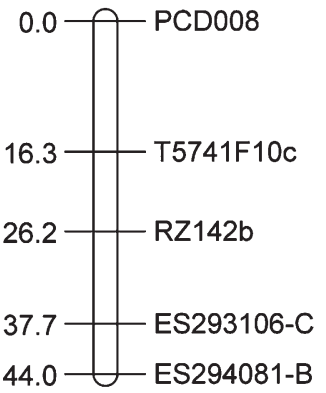

$2 a$

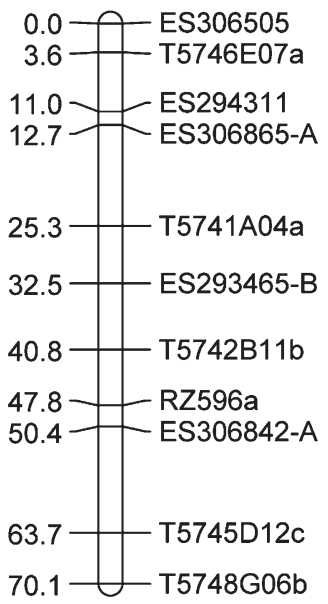

$2 d$

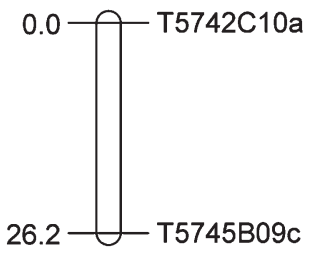

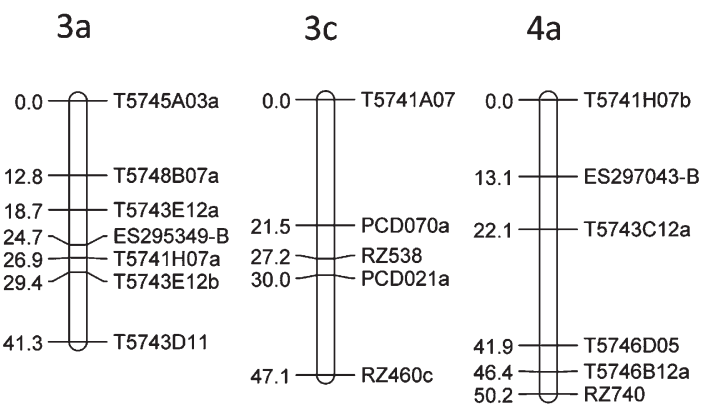

\section{5 a $\& 15$}

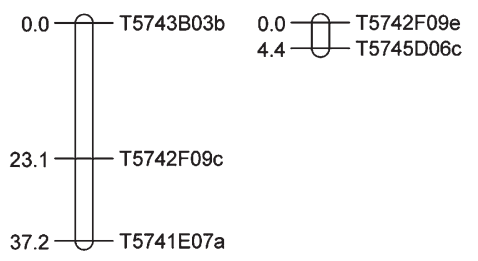

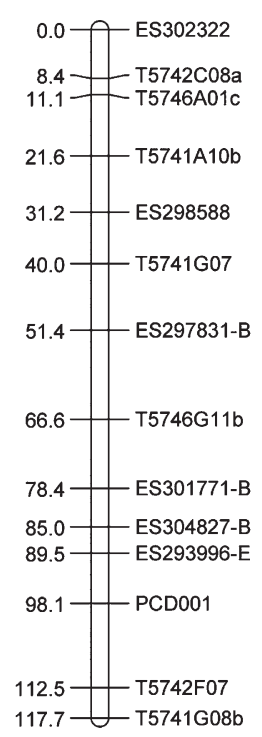

Fig. 2. T89 $(2 \mathrm{n}=4 \mathrm{x}=36)$ bermudagrass linkage groups formed with 125 single-dose amplified fragments (SDAFs) that include expressed sequence tag-simple sequence repeat (EST-SSR) markers. Map distances are in cM and linkage groups labeled with asterisks refer to linkage groups not previously identified by Bethel et al. (2006). 
$6 a$

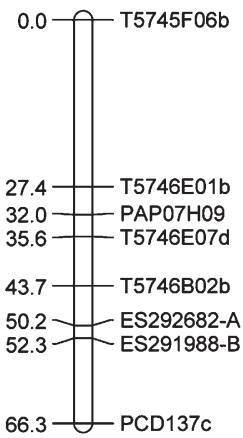

11

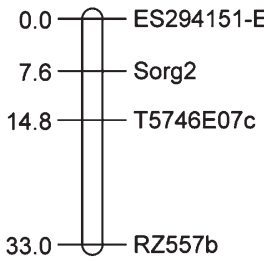

$7 a$

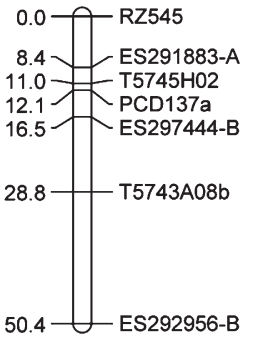

12

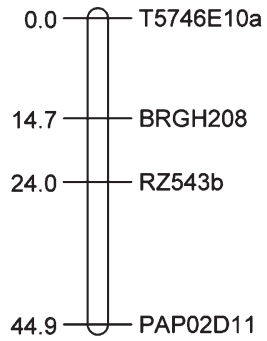

$8 b$

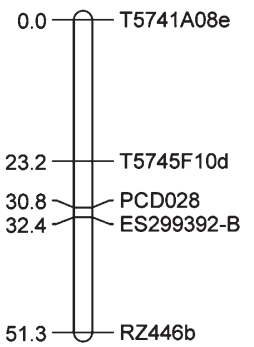

9

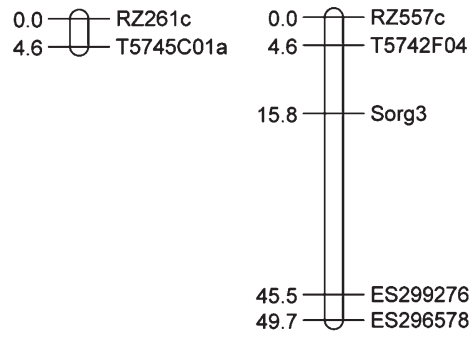

13

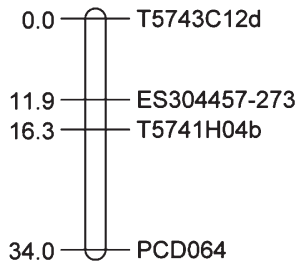

14

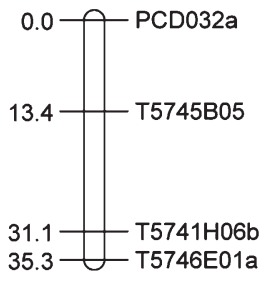

16

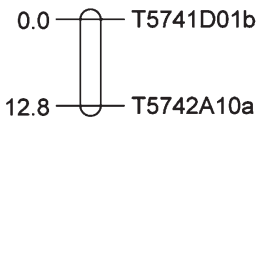

17

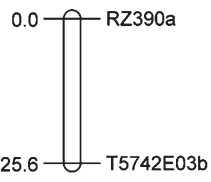

19

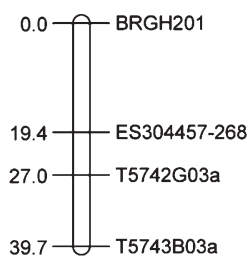

$20 *$

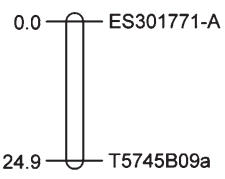

$21^{*}$
$22 *$

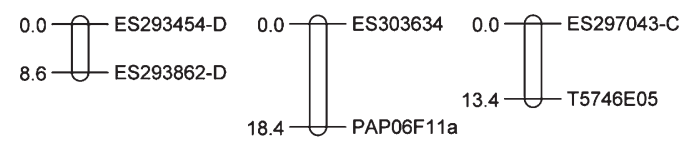

Fig. 2. (Continued).

Meiotic chromosome behavior was examined for several tetraploid C. dactylon accessions (Forbes and Burton, 1963). For 'Coastal' bermudagrass, cells at diakinesis had an average of 0.15 Is, $16.00 \mathrm{IIs}$, and $0.96 \mathrm{IVs}$, whereas a PI, PI226011, had averages of $1.36 \mathrm{Is}, 15.69 \mathrm{II}, 0.18 \mathrm{IIIs}$, and $0.68 \mathrm{IVs}$ (Forbes and Burton, 1963). In a follow-up study (Hanna and Burton, 1977) with four tetraploid $C$. dactylon cultivars, the majority of chromosome configurations at metaphase I were bivalents as well. For example, they showed the cultivar Midland had two Is, 17 IIs, 0 IIIs, and 0.39 IVs. Genome allopolyploids in meiosis are limited to bivalent pairing (Soltis and Soltis, 2000) and autotetraploids can form bivalents, quadrivalents, and a univalent and trivalent with a maximum frequency of two bivalents at $10 \%$ (Burnham, 1962). Thus, their data support tetraploid bermudagrass as an allopolyploid.

Genetic mapping of loci generated from probes of bermudagrass genomic clones and cDNA from Pennisetum spp. and rice (Oryza sativa) (Bethel et al., 2006), bermudagrass resistance gene analogs (Harris et al., 2010), and EST-SSR markers generated 333 single-dose markers of which 125 markers mapped on 26 T89 linkage groups spanning $1055 \mathrm{cM}$ and 36 single-dose markers mapped on eight T574 linkage groups spanning $311.1 \mathrm{cM}$. In comparison with the Bethel et al. (2006) map, four additional T89 linkage groups were identified that were composed primarily of ESTs and bermudagrass resistance gene homologs (Fig. 2, linkage groups 20 to 23) and some linkage groups were merged or split apart. For example, markers that formed linkage group $4 \mathrm{c}$ on the Bethel et al. (2006) map formed two separate linkage groups and Bethel linkage groups 5a and 15 were merged in this study. Furthermore, Bethel et al. (2006) identified 35 T89 linkage groups, whereas we identified 26 linkage groups of which nine were made of only two markers (Fig. 2, linkage groups $2 \mathrm{~d}, 4 \mathrm{c}, 9$, $16,17,20,21,22$, and 23) and likely, with the addition of more markers, could be mapped on existing linkage groups or merged. For an allotetraploid, the number of expected linkage groups would be 18 . For the T574 map, eight linkage groups were identified in this study instead of the 18 linkage groups identified by Bethel et al. (2006). For a diploid, one linkage group per chromosome pair would be expected. Thus, for C. transvaalensis, nine linkage groups would be expected and eight were identified (Fig. 3). The efficiency of mapping markers in bermudagrass is quite low because many are removed for not having 1:1 segregation and many did not map. More markers, preferably using a marker system that generates a large number of fragments such as AFLPs, are needed to increase the density of the map so that all linkage groups can be identified. 

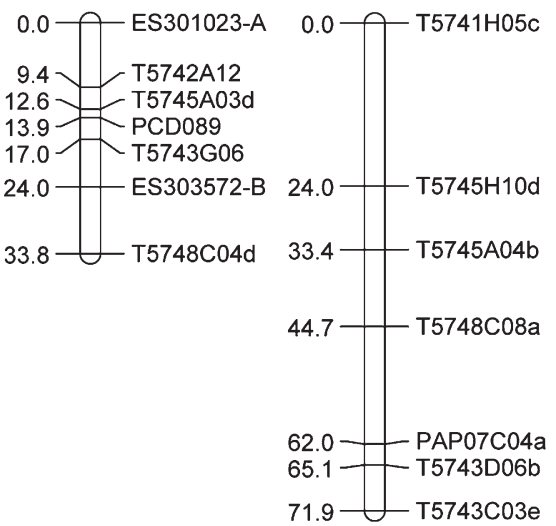

$7 b$

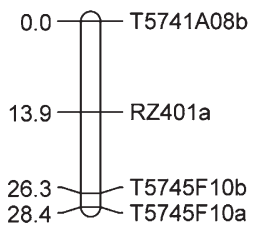

9

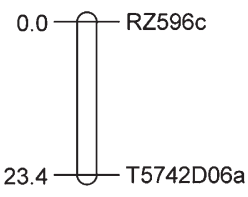

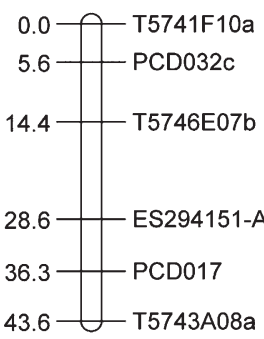

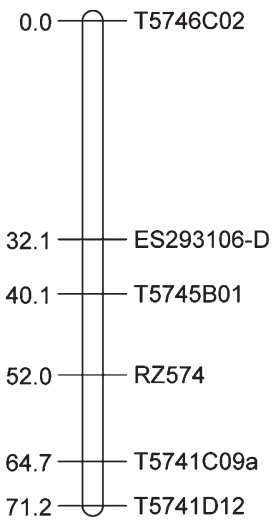

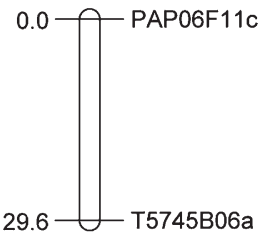

10

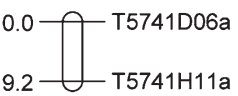

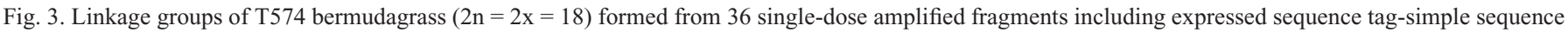
repeat (EST-SSR) markers. Map distances are in cM and linkage groups are named based on the Bethel et al. (2006) designation.

Twenty-eight bermudagrass EST-SSR markers could be mapped to the T89 (24 markers) and T574 (four markers) genetic maps (Table 3 ). It is possible that more EST-SSR markers mapped to the T89 linkage map rather than the T574 linkage map because the EST sequences were generated from genotype T89 (Kim et al., 2008). These 28 EST-SSR markers grouped on 17 linkage groups (Table 3; Figs. 1 and 2). The largest number of SSR markers (four) mapped to the T89 linkage groups $2 \mathrm{a}$ and $5 \mathrm{a}$ and 15. Mapped EST-SSRs with multiple alleles could be identified. Five EST primers had two mapped alleles (ES292682a, b T89 6a, 1a; ES297043b, c T89 4a, 23; ES301771a, b T89 20, 5a and 15; ES304457-268, 273 T89 19, 13; ES306865a, b T89 2a, 1a) that mapped to different linkage groups on the T89 map and may link homologous linkage groups. Two EST primers (ES293106c, d T89 1c/T574 6a; ES294151a,e T89 4a/T89 11) have alleles that mapped to the T89 and T574 genetic maps. Two RFLP markers (T5742F09c, e T89 4c; T5743E12a, b T89 3a; T5745F10a, b T574 7b) map on the same linkage group and may represent duplication events. Further marker data (that generate multiple alleles from a single locus) linking the T89 and T574 linkage groups are needed before homoeologous or homologous (for T89) linkage group assignments can be made.

Similarity OF CYNODON LINKAGE GROUPS TO RICE AND SORGHUM CHROMOSOMES. EST sequences of the 28 bermudagrass EST-SSRs were compared with rice and sorghum (Sorghum bicolor) chromosomes using BLASTn analysis (Table 3). ESTSSR markers that mapped to T89 linkage group 7a had strong similarity to rice chromosome 3 and sorghum chromosome 1 . EST-SSR markers on linkage group $2 \mathrm{a}$ had similarity to rice chromosomes 6 and 3. Many linkage groups only contained a couple of EST-SSRs, but the BLASTn similarity data to rice or sorghum chromosomes are in agreement with previously collected RFLP data from linkage groups both maps have in common (Bethel, 2005).

ABILITY OF SIMPLE SEQUENCE REPEATS TO DISTINGUISH MUTATED VERSUS CONTAMINATED SAMPLES FOR 'TIFGREEN'-DERIVED CULTIVARS. SSRs are a highly polymorphic marker system and can be used to determine genetic relationships among samples and to identify cultivars (Doveri et al., 2008). Although genetic relationships of many of the bermudagrass cultivars have been examined extensively (Chen et al., 2009; Ho et al., 1997; Wang et al., 2009; Zhang et al., 1999), no single locus marker system has been successful in identifying cultivars, or their off-types, derived from the mutation-prone 'Tifgreen'. These cultivars derived from 'Tifgreen' include MiniVerde, MS Supreme, Tifdwarf, FloraDwarf, Jones Dwarf, and Champion. A large demand exists from golf course superintendents and turfgrass breeders to be able to identify contaminants from true off-types (K.R. Harris-Shultz and B.M. Schwartz, unpublished data). PCR products from the 53 primer pairs were amplified using 'Tifgreen', 'Tifdwarf', 'FloraDwarf', 'Jones Dwarf', 'Champion', two sources of 'MiniVerde', two off-types of 'MiniVerde', and 'TifEagle'. These 10 samples had previously been examined using 11 AFLP EcoRI, MseI combinations and proved to be nearly indistinguishable (data not shown) and thus are likely true somatic mutants. Identical alleles for the EST-SSR markers were seen for all samples. This confirms that these EST-SSR markers are useful in determining if these lines are related to 'Tifgreen' but cannot differentiate each off-type.

The bermudagrass EST-SSR markers were also used to determine if 'Tifgreen'-derived cultivar off-types are related to 'Tifgreen' or contaminants. Two samples of 'Tifdwarf' off-types and two "normal"-looking 'Tifdwarf' samples were sent from 
Table 3. Twenty-eight bermudagrass expressed sequence tag-simple sequence repeat (EST-SSR) markers that mapped to a T89 or to a T574 linkage group.

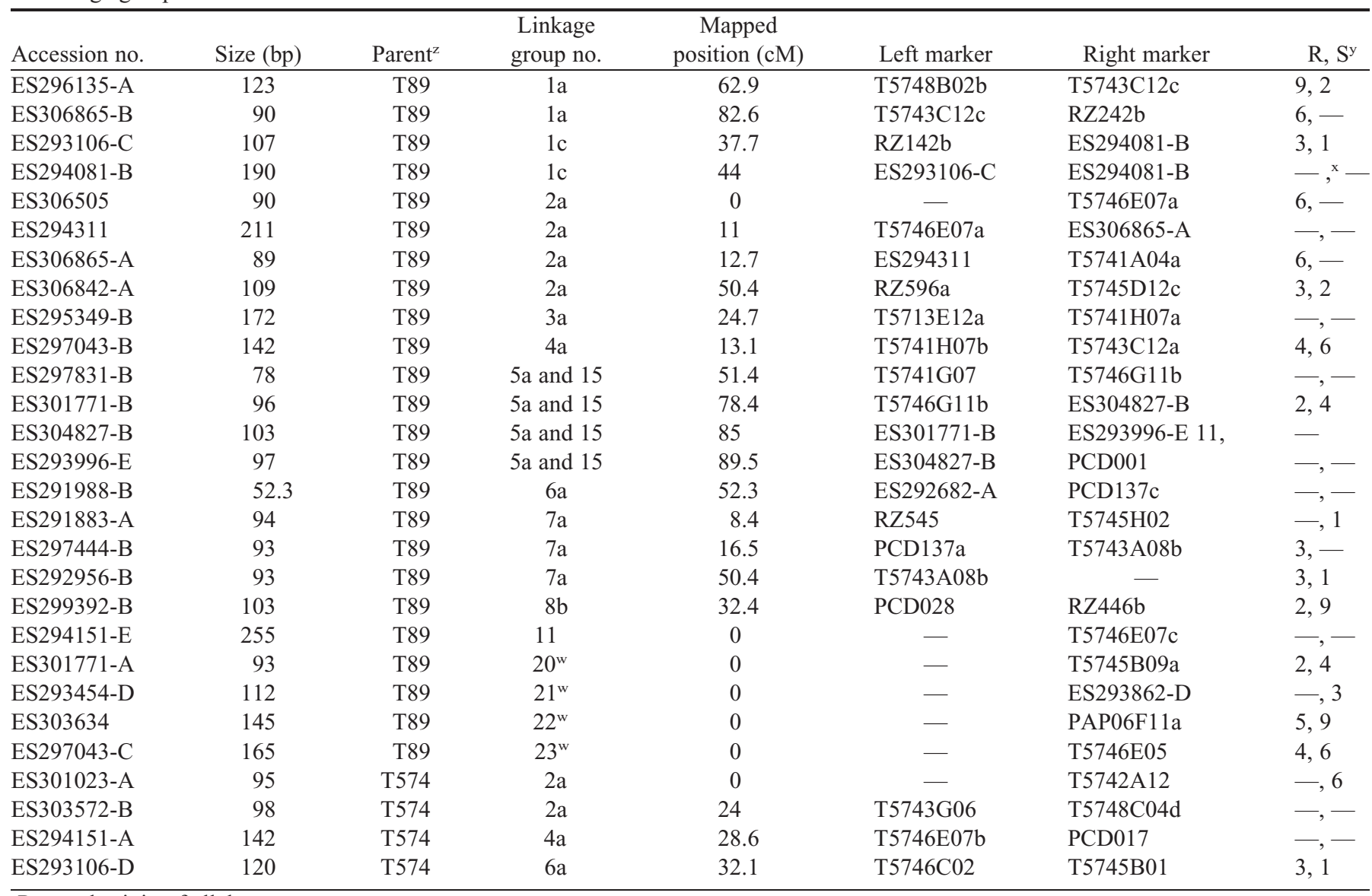

${ }^{\mathrm{z}}$ Parental origin of allele.

${ }^{\mathrm{y}} \mathrm{R}=$ rice; $\mathrm{S}=$ sorghum.

${ }^{\mathrm{x}}$ No strong BLASTn hits.

${ }^{w}$ Linkage group not identified by Bethel et al. (2006).

a Florida golf course and ploidy analysis was conducted on each. By flow cytometry, each sample was confirmed as being a triploid. Next, 16 EST-SSRs were amplified from the 10 genotypes described previously the two 'Tifdwarf' off-types and two control 'Tifdwarf' samples sent from the golf course and four additional triploids ('Tifway', 'Tifway II', 'TifSport', and 'TifGrand') were run for possible identification of the two offtypes. From 16 EST-SSRs, 56 markers were generated and the off-types could be classified as either contamination (Fig. 4; BT1) or related to 'Tifgreen' (Fig. 4; BT2, BT3, BT4). Thus, these EST-SSRs are useful in identifying contaminants or if samples are related to 'Tifgreen'.

The bermudagrass EST-SSR markers are also useful in confirming or refuting pedigrees (Fig. 4). For example, 'TifEagle' is reported to be derived from an irradiated stolon of 'Tifway II' (Hanna and Elsner, 1999) yet AFLP and EST-SSR data from this study show a close genetic similarity to 'Tifgreen' (Supplementary Fig. 2; Fig. 4). This finding has also been seen in other molecular studies (Chen et al., 2009; Zhang et al., 1999). Thus, these data suggest that 'TifEagle' is derived from 'Tifgreen'. Also 'TifSport' is reported to be derived from irradiated 'Midiron' stolons (Hanna et al., 1997), yet AFLP and SSR data from this study show very close genetic similarity to 'Tifway' and 'Tifway II'(Supplementary Fig. 2; Fig. 4). Similar results were reported by Chen et al. (2009) and Yerramsetty et al. (2008). These data suggest that 'TifSport' could be derived from irradiated 'Tifway' or 'Tifway II' stolons. This study also shows that the newly released 'TifGrand' bermudagrass, formerly known as shade-tolerant 5 (ST-5) during its evaluation, has some unique alleles different from any other triploid released by the Tifton breeding program but is genetically similar (55\%, EST-SSR data) to 'Tifway', 'Tifway II', and 'TifSport' (Fig. 4). This finding has been confirmed by Chen et al. (2009). The similarity of 'TifGrand' to 'Tifway', 'Tifway II', and 'TifSport' may be because it shares a similar parent in its pedigree. Thus, the bermudagrass EST-SSRs we created are useful in pedigree identification, which is informative, because bermudagrass is invasive and can easily contaminate other cultivar fields.

In this article, two genetic maps of $C$. transvaalensis and C. dactylon were enriched using data from probes previously developed from bermudagrass genomic clones and cDNA from Pennisetum spp. and rice (Bethel et al., 2006), bermudagrass resistance gene analogs (Harris et al., 2010), and the newly created EST-SSR markers. Although more work is needed to saturate these maps, these newly developed EST-SSRs are of particularly high value for determining genetic diversity among samples and for cultivar or contaminant identification. 


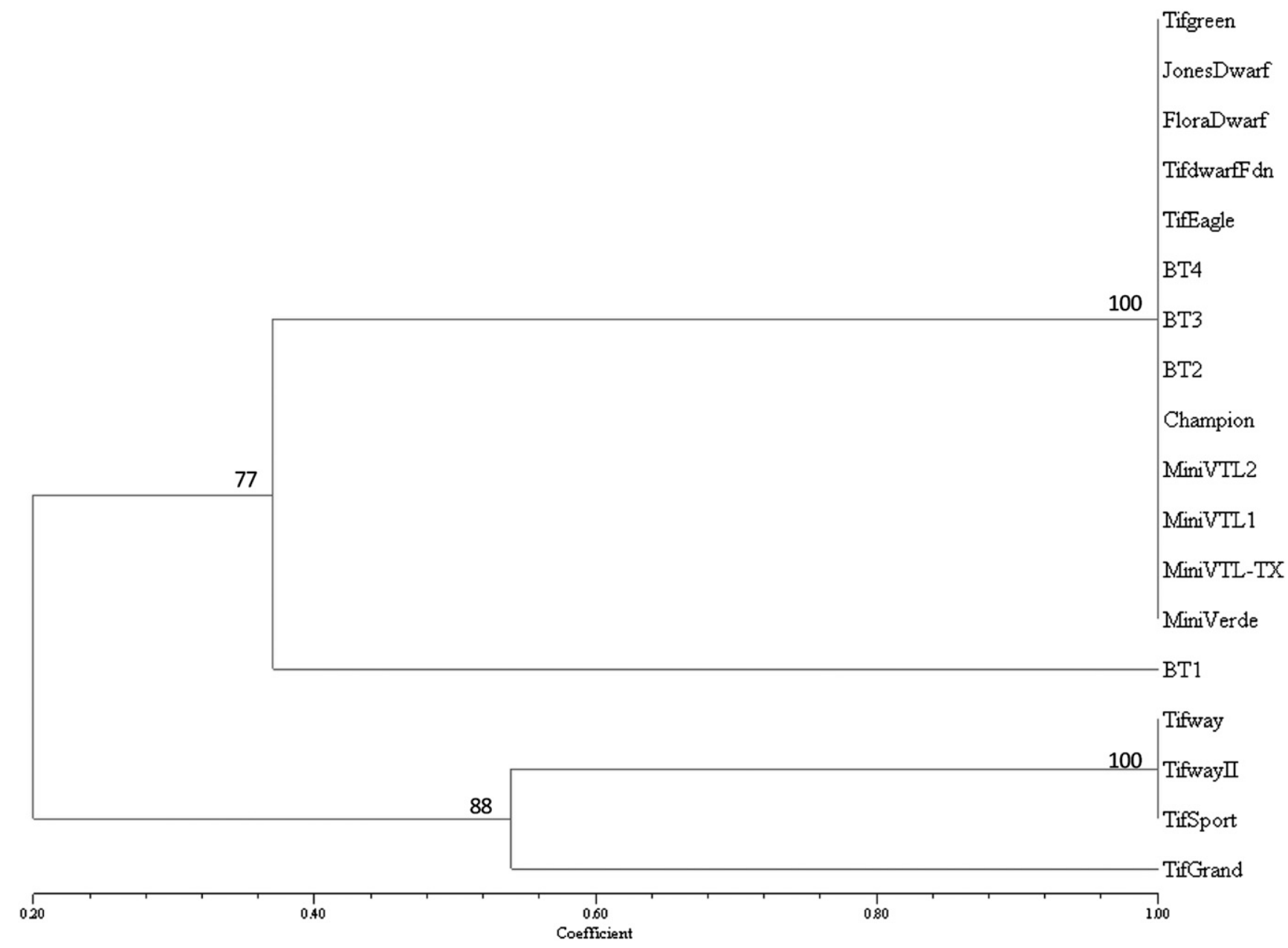

Fig. 4. Bermudagrass expressed sequence tag-simple sequence repeat (EST-SSR) markers cannot differentiate samples that are off-types of 'Tifgreen' but can distinguish samples that are contaminants from 'Tifgreen'-derived cultivar fields or greens.

\section{Literature Cited}

Al-Janabi, S.M., R.J. Honeycutt, M. McClelland, and B.W.S. Sobral. 1993. A genetic linkage map of Saccharum spontaneum L. 'SES 208'. Genetics 134:1249-1260.

Bethel, C.M. 2005. A framework linkage map of bermudagrass (Cynodon dactylon $\times$ Cynodon transvaalensis) based on single-dose restriction fragments. MS thesis,. Univ. of Georgia, Athens, GA.

Bethel, C.M., E.B. Sciara, J.C. Estill, J.E. Bowers, W. Hanna, and A.H. Paterson. 2006. A framework linkage map of bermudagrass (Cynodon dactylon $\times$ transvaalensis) based on single-dose restriction fragments. Theor. Appl. Genet. 112:727-737.

Boutin-Ganache, I., M. Raposo, M. Raymond, and C.F. Deschepper. 2001. M13-tailed primers improve the readability and usability of microsatellite analyses performed with two different allele-sizing methods. Biotechniques 31:25-28.

Burnham, C.R. 1962. Discussion in cytogenetics. Burgess Publishing, Minneapolis, MN.

Chen, Z., M.L. Wang, C. Waltz, and P. Raymer. 2009. Genetic diversity of warm-season turfgrass: Seashore paspalum, bermudagrass, and zoysiagrass revealed by AFLPs. Floriculture Ornamental Biotechnol. 3:20-24.

Da Silva, J.A.G., M.E. Sorrells, W.L. Burnquist, and S.D. Tanksley. 1993. RFLP linkage map and genome analysis of Saccharum spontaneum. Genome 36:782-791.

Doveri, S., F.S. Gil, A. Diaz, S. Reale, M. Busconi, A.C. Machado, A. Martin, C. Fogher, P. Donini, and D. Lee. 2008. Standardization of a set of microsatellite markers for use in cultivar identification studies in olive (Olea europaea L.). Sci. Hort. 116:367-373.

Forbes, I. and G.W. Burton. 1963. Chromosome numbers and meiosis in some Cynodon species and hybrids. Crop Sci. 3:75-79.

Fregene, M., F. Angel, R. Gomez, F. Rodriguez, P. Chavarriaga, W. Roca, J. Tohme, and M. Bonierbale. 1997. A molecular genetic map of cassava (Manihot esculenta Crantz). Theor. Appl. Genet. 95:431441.

Hampl, V., A. Pavlícek, and J. Flegr. 2001. Construction and bootstrap analysis of DNA fingerprinting-based phylogenetic trees with a freeware program FreeTree: Application to trichomonad parasites. Intl. J. Syst. Evol. Microbiol. 51:731-735.

Hanna, W.W. and G.W. Burton. 1977. Cytological and fertility characteristics of some hybrid bermudagrass cultivars. Crop Sci. 17: 243-245.

Hanna, W.W., R.N. Carrow, and A.J. Powell. 1997. Registration of 'Tift94' bermudagrass. Crop Sci. 37:1012.

Hanna, W.W. and J.E. Elsner. 1999. Registration of 'TifEagle' bermudagrass. Crop Sci. 39:1258.

Harris, K.R., W. Anderson, and R. Malik. 2009. Genetic diversity among napiergrass (Pennisetum purpureum Schum.) nursery accessions using AFLP markers. Plant Genet. Resources 8:63-70.

Harris, K.R., B.M. Schwartz, A.H. Paterson, and J.A. Brady. 2010. Identification and mapping of nucleotide binding site-leucine-rich repeat resistance gene analogs in bermudagrass. J. Amer. Soc. Hort. Sci. 135:74-82. 
Ho, C.Y., S.J. McMaugh, A.N. Wilton, I.J. McFarlane, and A.G. Mackinlay. 1997. DNA amplification variation within cultivars of turf-type Couch grasses (Cynodon spp.). Plant Cell Rep. 16:797-801. Kim, C., C.S. Jang, T.L. Kamps, J.S. Robertson, F.A. Feltus, and A.H. Paterson. 2008. Transciptome analysis of leaf tissue from bermudagrass (Cynodon dactylon) using a normalized cDNA library. Funct. Plant Biol. 35:585-594.

Kosambi, D.D. 1944. The estimation of map distances from recombination values. Ann. Eugen. 12:172-175.

Missaoui, A.M., A.H. Paterson, and J.H. Bouton. 2005. Investigation of genomic organization in switchgrass (Panicum virgatum L.) using DNA markers. Theor. Appl. Genet. 110:1372-1383.

Nei, M. and W.H. Li. 1979. Mathematical model for studying genetic variation in terms of restriction endonucleases. Proc. Natl. Acad. Sci. USA 76:5269-5273.

Rieseberg, L.H. and R.D. Noyes. 1998. Genetic map-based studies of reticulate evolution in plants. Trends Plant Sci. 3:254-259.

Riley, R.J. 2000. Cynodon dactylon plant named 'Riley's Super Sport'. Plant Patent PP11181. U.S. Patent and Trademark Office, Washington, DC.

Rohlf, F.J. 2008. NTSYSpc: Numerical taxonomy system. Version 2.20. Exeter Publishing, Setauket, NY.

Rozen, S. and H.J. Skaletsky. 2000. Primer3 on the WWW for general users and for biologist programmers, p. 365-386. In: Krawetz, S. and S. Misener (eds.). Bioinformatics methods and protocols: Methods in molecular biology. Humana Press, Totowa, NJ.

Soltis, P.S. and D.E. Soltis. 2000. The role of genetic and genomic attributes in the success of polyploids. Proc. Natl. Acad. Sci. USA 97:7051-7057.

Stein, J., S.C. Pessino, E.J. Martinez, M.P. Rodriguez, L.A. Siena, C.L. Quarin, and J.P.A. Ortiz. 2007. A genetic map of tetraploid Paspalum notatum Flugge (bahiagrass) based on single-dose molecular markers. Mol. Breed. 20:153-166.

Taliaferro, C.M., D.L. Martin, J.A. Anderson, M.P. Anderson, G.E. Bell, and A.C. Guenzi. 2003. Registration of 'Yukon' bermudagrass. Crop Sci. 43:1131-1132.

Utrillas, M.J. and L. Alegre. 1997. Impact of water stress on leaf anatomy and ultrastructure in Cynodon datylon (L.) Pers. under natural conditions. Intl. J. Plant Sci. 158:313-324.

Van Ooijen, J.W. 2006. Joinmap 4. Software for the calculation of genetic linkage maps in experimental populations. Kyazma, Wageningen, The Netherlands.

Walker, N.R., T.K. Michell, A.N. Morton, and S.M. Marek. 2006. Influence of temperature and time of year on colonization of bermudagrass roots by Ophiosphaerella herpotricha. Plant Dis. 90: 1326-1330.

Wang, Z., X. Yuan, Y. Zheng, and J. Liu. 2009. Molecular identification and genetic analysis for 24 turf-type Cynodon cultivars by sequencerelated amplified polymorphism markers. Sci. Hort. 122:461-467.

Webster, T.M., W. Hanna, and B.G. Mullinix. 2004. Bermudagrass (Cynodon spp.) dose-response relationships with clethodim, glufosinate and glyphosate. Pest Manag. Sci. 60:1237-1244.

Wu, K.K., W. Burnquist, M.E. Sorrells, T.L. Tew, P.H. Moore, and S.D. Tanksley. 1992. The detection and estimation of linkage in polyploids using single-dose restriction fragments. Theor. Appl. Genet. 83:294-300.

Yerramsetty, P.N., M.P. Anderson, C.M. Taliaferro, and D.L. Martin. 2008. Genetic variations in clonally propagated bermudagrass cultivars identified by DNA fingerprinting. Plant Omics J. 1:1-8.

Zhang, L.H., P. Ozias-Akins, G. Kochert, S. Kresovich, R. Dean, and W. Hanna. 1999. Differentiation of bermudagrass (Cynodon spp.) genotypes by AFLP analyses. Theor. Appl. Genet. 98:895-902. 